\author{
Alberto Pilotto - Marilisa Franceschi - Dino Vitale • \\ Augusto Zaninelli - Giulio Masotti - Franco Rengo • \\ F.I.R.I. (Fondazione Italiana Ricerca Invecchiamento) • \\ SOFIA Project Investigators

\section{Drug use by the elderly in general practice: effects on upper gastrointestinal symptoms}

Received: 22 March 2005 / Accepted: 1 August 2005 / Published online: 30 December 2005

(C) Springer-Verlag 2005

\begin{abstract}
Objective: To evaluate the prevalence of drug use by elderly outpatients in Italy and to identify the association between drug use and gastrointestinal symptoms. Study design and setting: The study was carried out by 133 general practitioners (GPs) who referred to 24 geriatric units in Italy. All consenting elderly patients seen at the GPs' offices were evaluated for gender, age, disability, current medications, and upper gastrointestinal symptoms. Results: The study included 5,515 elderly subjects. The prevalence of drug use was $91.6 \%$, and the mean number of drugs taken was 2.86 per person. Both the prevalence and the mean number of drugs significantly increased with advancing age. Regarding gastrointestinal symptoms, $32.7 \%$ of patients reported at least one upper gastrointestinal symptom: $25 \%$ with indigestion syndrome, $16.2 \%$ with abdominal pain, and $14.2 \%$ with reflux symptoms. A significantly higher prevalence of symptoms was observed in females, patients who were taking a higher number of drugs, and those who had higher disability. Adjusted mul-
\end{abstract}

\footnotetext{
A. Pilotto $(\bowtie) \cdot$ M. Franceschi

Geriatric Unit, Casa Sollievo della Sofferenza, IRCCS,

71013 San Giovanni Rotondo, Italy

e-mail: alberto.pilotto@libero.it

Tel.: +39-0882-410271

Fax: +39-0882-410271

D. Vitale $\cdot$ F. Rengo

Clinical Epidemiology Service,

Fondazione Maugeri, IRCCS,

Telese Terme, Italy

A. Zaninelli

Romano di Lombardia and University of Firenze,

Italy

G. Masotti

Geriatric Unit, University of Firenze,

Italy

F. Rengo

Geriatric Unit, University of Napoli,

Italy
}

tivariate analysis demonstrated that the use of nonsteroidal antiinflammatory drugs, steroids, psycholeptics, diuretics, selective $\beta_{2}$ adrenoreceptor agonists or adrenergics, and antiplatelet drugs was significantly associated with upper gastrointestinal symptoms. Conclusion: The prevalence of drug use is very high in this elderly outpatient population. The number of drugs and the use of some specific drug classes are significantly associated with the presence of upper gastrointestinal symptoms.

Keywords Drug use · Elderly - Gastrointestinal symptoms $\cdot$ Pharmacoepidemiology

\section{Introduction}

The prevalence of drug use [1] and the prevalence of adverse drug reactions (ADRs) increase with advancing age [2]. Reports from the Italian Group of Pharmacoepidemiology in the Elderly (GIFA) [3], based on 28,411 patients consecutively admitted to 81 hospitals throughout Italy, describe gastrointestinal (GI) problems as the most common ADR (19\%) from a total incidence of 3.4\% (964 of 28,411$)$. GI disorders were also the most frequent adverse drug event (ADE; 32.1\% of a total incidence of $14.6 \%$ ) observed in a prospective study performed in elderly patients aged 70 years and older who were consecutively admitted to a general hospital in the United States and monitored daily for ADE occurrence [4]. More recently, a cohort study of all Medicare patients aged 65 years and older cared for by a multispecialty group practice during a 1-year period reported that GI tract disorders were the most frequent ADEs (22.1\%) from an overall rate of 50.1 per 1,000 person-years [5].

At present, no data are available on the prevalence of drug use and GI symptoms in elderly outpatients in the ambulatory setting. The aim of the present study was to evaluate the prevalence of drug use by elderly outpatients in Italy and the association between drug use and GI disorders in elderly patients managed by their general practitioners (GPs). 


\section{Materials and methods}

\section{Selection of GPs}

The study was funded by the Italian Foundation for Research on Aging (FIRI) and was carried out by 133 GPs. At the study's conception, 192 GPs were randomly identified from local GP lists, 188 of whom attended a preliminary meeting to receive information about the aims, methods, and design of this study. The meetings were carried out by 24 educated specialists in geriatrics from 24 different geriatric units in Italy. Of 188 GPs who attended the meetings, 133 agreed to carry out the investigation.

\section{Inclusion criteria}

The investigation was performed from March to June 2003. GPs included into the study all patients seen during a 2week period (10 working days) who accepted participation in the study. All subjects aged 65 years and over who sought their GP for a medical problem during this 2-week period were included in the study. Elderly patients who were visited in their homes or in nursing homes were not included.

\section{Data collection}

Data were obtained by a structured interview of patients and/or their relatives and, when possible, were confirmed by the GPs' medical records. The interview was carried out by skilled GPs. A software PC instrument followed the interviewer step by step in collecting and recording the demographic and functional data as well as the information on drug use and GI symptoms. The software was designed in order to avoid the possibility of recording incomplete files by including obligatory answers for each demographic, functional, drug, and symptom category ("no" or "yes," and in the case of "yes," a guided specification of data).

Demographic data (age, gender), physical functions structured according to activities of daily living (ADL) [6] and instrumental activities of daily living (IADL) [7] questionnaires, current therapies, GI symptoms evaluated according to the gastrointestinal symptom rating scale (GSRS) [8], and other GI symptoms (vomiting, hematemesis, and/ or melena) were recorded. Records were computerized and e-mailed to the statistics reference center for evaluation.

\section{Physical functions}

Physical functions were assessed with standardized tests evaluating a patient's ability to perform six activities of daily living: bathing, dressing, transferring, walking, toileting, and eating [6]. Eight instrumental activities of daily living - managing finances, taking medications, using the telephone, shopping for food or clothes, washing, using transportation, preparing meals, and doing housework- were also evaluated [7]. We defined "severe disability" as a loss of three or more functions on the ADL and/or IADL questionnaires, "moderate disability" as a loss of two functions on the ADL and/or IADL questionnaires, "mild disability" as a loss of at least one function on the ADL and/or IADL questionnaires, and "no disability" as no loss in $\mathrm{ADL} / \mathrm{IADL}$ functions.

\section{Drug use}

Drug use was identified according to the Anatomical Therapeutics Chemical (ATC) classification code system [9]. In this system, drugs are divided into 14 main anatomical groups, each being further divided into two sublevels, therapeutic and pharmacological. During the interview, the names of specific drugs were recorded as well as the doses, the use patterns (acute, chronic, on demand), and the duration of treatment.

Patients were defined as drug users if they were taking a drug from any of the above described classes at the time of the visit.

\section{Upper Gastrointestinal symptoms}

Gastrointestinal symptoms were evaluated with the GSRS, modified for patients with upper GI disorders [8, 10]. The questionnaire includes 15 items for a description of upper (items 1-8) and lower (9-15) GI symptoms. The GSRS has been validated in elderly subjects with and without GI symptoms [11]. Because pathophysiology and clinical meaning of upper GI symptoms differ from those of lower GI symptoms, we evaluated the association between drug use and GI symptoms separately for the upper and lower GI tracts. Only the following items were evaluated in the present study:

- Abdominal pain syndrome (item 1: stomach ache or pain; item 4: hunger pains in the stomach)

- Reflux syndrome (item 2: heartburn; item 3: acid reflux)

- Indigestion syndrome (items 5: nausea; 6: rumbling in the stomach, i.e. vibrations or noise in the stomach; 7 : bloating or swelling in the stomach; 8: burping, i.e. bringing up air or gas through the mouth).

Items that described diarrhea and constipation syndromes (items 9-15) were not reported in the study. The GSRS questionnaire included a response scale with seven grades; we defined symptomatic patients as those who reported mild, moderate, or severe discomfort in at least one item [11]. Moreover, the presence of vomiting, melena, and/or hematemesis was recorded.

\section{Statistics}

Statistical analysis was performed using the SPSS version 11.5 for Windows statistical software package. The Pearson chi-square and the Fisher exact or Student's $t$-tests, when 
appropriate, were used for the comparison of demographic characteristics (gender, age), overall drug use, specific drug use, and GI symptoms. A multivariate analysis was used to evaluate potential correlations between sex, age, ADL, IADL, specific drug use, and GI symptoms. A binary logistic regression model was used to compute odds ratio (OR) and relative 95\% confidence intervals (CI) of independent variables. The maximum likelihood method was used for entering and removing variables and for calculating variable interaction. All $p$-values were twotailed, with statistical significance indicated by a value of $p<0.05$.

\section{Results}

Study population: demographic and functional characteristics

During the study period, 5,533 subjects were interviewed by 133 GPs. Eighteen subjects were excluded because they did not fulfill inclusion criteria (age 65 years or over). Thus, the final evaluation was performed in 5,515 elderly subjects (2,519 males, 2,996 females, mean age $75.01 \pm 6.2$ years, range $65-100$ years).

Table 1 shows the demographic and functional characteristics of the study population according to geographical area (northern, central, and southern Italy). No differences were found among these three geographical areas regarding mean age. However, significant differences were found regarding gender (females: northern $57.7 \%$, central $55.2 \%$, southern $50.3 \%, p=0.0001$ ) and the prevalence of disability identified by the ADL (northern $14.5 \%$, central $14 \%$, southern $17.3 \%$, $p<0.05$ ) and IADL scores (northern 28\%, central 43\%, southern $39.4 \%, p=0.0001)$.

Overall drug use

Of 5,515 subjects, 5,053 (91.6\%) were taking at least one drug, with a statistically significant difference observed between males and females $(90.6 \%$ vs. $92.5 \%, p=0.017$; Table 2). The drug use rates were significantly higher in patients from northern vs. central and southern Italy ( $94.2 \%$ vs. $91.5 \%$ vs. $89.4 \%, p=0.0001$; Table 1$)$.

Specific drugs taken by the elderly are reported in Table 2. Cardiovascular drugs, i.e., ACE inhibitors (32.4\%) and calcium antagonists $(22.5 \%)$, were those most frequently taken. Low-dose aspirin was taken by $20.6 \%$ of subjects. Other pharmacological classes used with great frequency were GI drugs (19.7\%), nervous system drugs $(17.2 \%)$, and musculoskeletal drugs (15.4\%).

Compared with men, women took significantly more angiotensin II antagonists ( $14.3 \%$ vs. 9.5\%, $p=0.0001)$; serum lipid-reducing agents $(15.0 \%$ vs. $13.0 \%, p=0.039)$; nervous system drugs, i.e., psycholeptics $(14.1 \%$ vs. $6.3 \%$, $p=0.0001)$ and psychoanaleptics $(9.5 \%$ vs. $4.1 \%, p=$ $0.0001)$; musculoskeletal drugs $(19 \%$ vs. $11.1 \%, p<$ $0.0001)$; vitamin and mineral supplements $(8.4 \%$ vs. $1.7 \%, p=0.0001)$; and thyroid therapy $(7.3 \%$ vs. $1.8 \%$, $p<0.0001)$. Conversely, compared with women, men took more low-dose aspirin $(23.5 \%$ vs. $18.2, p<0.0001)$, antithrombotic agents $(11.7 \%$ vs. $7.5 \%, p<0.0001)$, organic nitrates $(10.8 \%$ vs. $7.3 \%, p=0.0001)$, calcium channel blockers $(25.5 \%$ vs. $20.1 \%, p=0.0001)$, drugs for the urogenital system $(19.4 \%$ vs. $1.3 \%, p<0.0001)$, drugs for

Table 1 Demographic and functional characteristics and prevalence of drug use by elderly subjects divided according to Italian regional geographical area (GPs general practitioners)

\begin{tabular}{lllll}
\hline & North & Central & South/islands & Total \\
\hline Number of patients & 2,189 & 1,201 & 2,125 & 5,515 \\
Number of GPs & 54 & 27 & 52 & 133 \\
Patients/GPs & 40.5 & 44.7 & 40.9 & 41.8 \\
Females, number (\%) & $1,263(57.7 \%)$ & $663(55.2 \%)$ & $1,070(50.3)^{\mathrm{a}}$ & $2,996(54.3 \%)$ \\
Males, number (\%) & $926(42.3 \%)$ & $538(44.8 \%)$ & $1,055(49.6 \%)$ & $2,519(45.7 \%)$ \\
Mean age \pm SD & $75.07 \pm 6.3$ & $74.97 \pm 6.1$ & $74.94 \pm 6.1$ & $75.01 \pm 6.2$ \\
Prevalence of drug use \% & 94.2 & $91.5^{\mathrm{b}}$ & $89.4^{\mathrm{b}}$ & \\
Physical function & & & & \\
Activities of daily living questionnaire & & & $1,637(82.8 \%)^{\mathrm{c}}$ & \\
No disability & $1,836(85.5 \%)$ & $1,019(86.0 \%)$ & $239(12.1 \%)$ & $4,492(84.6 \%)$ \\
Mild disability & $184(8.6 \%)$ & $107(9.0 \%)$ & $102(5.2 \%)$ & $530(10.0 \%)$ \\
Moderate/severe disability & $126(5.9 \%)$ & $59(5.0 \%)$ & & $287(5.4 \%)$ \\
Instrumental activities of daily living & questionnaire & & $1,198(60.6 \%)^{\mathrm{d}}$ & \\
No disability & $1,544(71.9 \%)$ & $675(57.0 \%)$ & $420(21.2 \%)$ & $3,417(64.4 \%)$ \\
Mild disability & $309(14.4 \%)$ & $276(23.9 \%)$ & $360(18.2 \%)$ & $1,005(18.4 \%)$ \\
Moderate/severe disability & $293(13.6 \%)$ & $234(19.7 \%)$ & $887(16.7 \%)$ \\
\hline
\end{tabular}

${ }^{\mathrm{a}}$ North vs. Central, $p=\mathrm{ns}$; North vs. South, $p=0.0001$; Central vs. South, $p=0.007$

${ }^{b}$ North vs. Central, $p=0.003$; North vs. South, $p=0.0001$; Central vs. South, $p=0.058$

${ }^{\mathrm{c}}$ North vs. Central, $p=\mathrm{ns}$; North vs. South, $p=0.02$; Central vs. South, $p=0.018$

${ }^{\mathrm{d}}$ North vs. Central, $p=0.0001$; North vs. South, $p=0.0001$; Central vs. South, $p=0.046$ 
Table 2 Prevalence of drug use in 5,515 elderly patients

\begin{tabular}{|c|c|c|c|c|c|}
\hline & Drug & $\begin{array}{l}\text { Total subjects } \\
n=5515(\%)\end{array}$ & $\begin{array}{l}\text { Females } \\
n=2996(\%)\end{array}$ & $\begin{array}{l}\text { Males } \\
n=2519(\%)\end{array}$ & $p$ \\
\hline$\underline{\mathrm{A}}$. & $\underline{\text { Gastroenterological apparatus }}$ & $1,087(19.7)$ & $579(19.33)$ & $508(20.17)$ & 0.748 \\
\hline A03.05 & $\begin{array}{l}\text { Drugs for functional gastrointestinal disorders } \\
\text { and bile and liver therapy }\end{array}$ & $191(3.46)$ & $139(4.6)$ & $52(2.06)$ & 0.0001 \\
\hline$\underline{\mathrm{A}}$. & $\underline{\text { Metabolism }}$ & $860(15.59)$ & $525(17.52)$ & $335(13.30)$ & 0.0001 \\
\hline $\mathrm{A} 10$ & Insulins and oral blood glucose-lowering drugs & $702(12.72)$ & $354(11.81)$ & $348(13.81)$ & 0.029 \\
\hline A11. 12. A14-15-16 & $\begin{array}{l}\text { Vitamin and mineral supplements, other } \\
\text { alimentary tract and metabolism products }\end{array}$ & $299(5.42)$ & $255(8.5)$ & $44(1.74)$ & 0.0001 \\
\hline$\underline{\mathrm{C}}$. & Cardiovascular system & $3,954(71.70)$ & $2,187(73.00)$ & $1,767(70.15)$ & 0.019 \\
\hline $\mathrm{C} 01$. & Cardiac therapy & $1,068(19.36)$ & $508(16.95)$ & $560(22.23)$ & 0.0001 \\
\hline $\mathrm{C} 02$. & Antiadrenergic agents & $299(5.42)$ & $149(4.97)$ & $150(5.95)$ & ns \\
\hline $\mathrm{C} 03$. & Diuretics & $836(15.16)$ & $458(15.29)$ & $378(15.01)$ & ns \\
\hline $\mathrm{C} 04 . \mathrm{C} 05$ & Peripheral vasodilators. vasoprotectives & $119(2.15)$ & $73(2.43)$ & $46(1.82)$ & ns \\
\hline $\mathrm{C} 07$. & Beta blockers & $588(10.66)$ & $338(11.28)$ & $250(9.92)$ & ns \\
\hline C08. & Calcium channel blockers & $1,243(22.54)$ & $601(20.06)$ & $642(25.49)$ & 0.0001 \\
\hline $\mathrm{C} 09$ & Agents acting on renin-angiotensin system & $2,457(44.55)$ & $1,406(46.92)$ & $1,051(41.72)$ & 0.0001 \\
\hline C09A-B & ACE inhibitors & $1,789(32.44)$ & $978(32.64)$ & $811(32.20)$ & ns \\
\hline$\underline{\text { M. }}$ & $\underline{\text { Musculoskeletal system }}$ & $850(15.41)$ & $569(18.99)$ & $281(11.15)$ & 0.0001 \\
\hline$\underline{\mathrm{N}}$. & $\underline{\text { Nervous system }}$ & $947(17.7)$ & $644(21.50)$ & $303(12.03)$ & 0.0001 \\
\hline N02.N03. N04.N07 & $\begin{array}{l}\text { Analgesic, antiepileptics, antiparkinson drugs, } \\
\text { other nervous system drugs }\end{array}$ & $288(5.22)$ & $151(5.04)$ & $137(5.43)$ & Ns \\
\hline N05 & Psycholeptics & $582(10.55)$ & $422(14.08)$ & $160(6.35)$ & $0.0001 \mathrm{~N} 06$ \\
\hline N06 & Psychoanaleptics & $389(7.05)$ & $285(9.51)$ & $104(4.12)$ & 0.0001 \\
\hline$\underline{\mathrm{P}}$ & $\frac{\text { Antiparasitic products, insecticides }}{\underline{\text { and repellents }}}$ & $17(0.31)$ & $15(0.50)$ & $2(0.08)$ & 0.005 \\
\hline$\underline{\mathrm{R}}$. & $\underline{\text { Respiratory system }}$ & $349(6.33)$ & $138(4.61)$ & $211(8.38)$ & 0.460 \\
\hline R01.R05. R06 & $\begin{array}{l}\text { Nasal preparations, cough/cold preparations, } \\
\text { and antihistamines for systemic use }\end{array}$ & $105(1.90)$ & $49(1.63)$ & $56(2.22)$ & Ns \\
\hline R03. & Drugs for obstructive airway diseases & $455(8.25)$ & $165(5.50)$ & $290(11.51)$ & 0.0001 \\
\hline$\underline{\mathrm{S}}$. & $\underline{\text { Sensory organs }}$ & $223(4.04)$ & $127(4.23)$ & $98(3.81)$ & 0.471 \\
\hline B0A1C06+-N02BA01 & $\begin{array}{l}\text { Blood and hemopoietic organs } \\
\text { and nervous system: low-dose aspirin }\end{array}$ & $1,138(20.63)$ & $545(18.19)$ & $593(23.54)$ & 0.0001 \\
\hline
\end{tabular}

obstructive airway diseases ( $11.5 \%$ vs. $5.5 \%, p=0.0001)$, and drugs for acid-related disorders (17.9\% vs. $15.0 \%$, $p=0.004)$.
The mean number of drugs taken by the elderly was 2.86 per person (males $=2.9 \pm 1.96$, females $=2.8 \pm 1.8$ ) with a range from 1 to 15 drugs per person. Both the prevalence 
Table 3 Drug use by the elderly population divided according to age

\begin{tabular}{|c|c|c|c|c|c|}
\hline & Total subjects & $65-74$ years & $75-84$ years & $>85$ years & $P$ \\
\hline Number of patients & 5,489 & 2,731 & 2,352 & 406 & \\
\hline Number of patients taking at least one drug (prevalence \%) & $5,030(91.6 \%)$ & $2,465(90.2 \%)$ & $2,181(92.7 \%)$ & $384(94.6 \%)$ & $<0.0001$ \\
\hline Mean number of drugs & 2.9 & 2.7 & 3.1 & 3.15 & \\
\hline A. Gastroenterological apparatus & $1,082(19.7 \%)$ & $549(20.1 \%)$ & $453(19.3 \%)$ & $80(19.7 \%)$ & 0.83 \\
\hline A. Metabolism & $858(15.6 \%)$ & $414(15.2 \%)$ & $376(16.0 \%)$ & $68(16.7 \%)$ & 0.67 \\
\hline $\mathrm{B}+-\mathrm{N}$. low-dose aspirin & $1,048(19.1 \%)$ & $374(13.7 \%)$ & $558(23.7 \%)$ & $116(28.6 \%)$ & $<0.0001$ \\
\hline B. Blood and hemopoietic organs & $576(10.5 \%)$ & $232(8.5 \%)$ & $296(12.6 \%)$ & $48(11.8 \%)$ & $<0.0001$ \\
\hline C. Cardiovascular system & $3,931(71.6 \%)$ & $1,859(68.7 \%)$ & $1,769(75.2 \%)$ & $303(74.6 \%)$ & 0.062 \\
\hline D. Dermatological & $43(0.78 \%)$ & $28(1.03 \%)$ & $13(0.55 \%)$ & $2(0.49 \%)$ & 0.13 \\
\hline G. Urogenital system and sex hormones & $522(9.5 \%)$ & $251(9.2 \%)$ & $235(9.99 \%)$ & $36(8.87 \%)$ & 0.62 \\
\hline H. Hormones for systemic use & $378(6.9 \%)$ & $206(7.5 \%)$ & $155(6.6 \%)$ & $17(4.2 \%)$ & 0.05 \\
\hline I. Antiinfective drugs for systemic use & $65(1.2 \%)$ & $35(1.3 \%)$ & $21(0.9 \%)$ & $9(2.2 \%)$ & 0.065 \\
\hline L. Antitumoral drugs and immunomodulators & $142(2.6 \%)$ & $71(2.6 \%)$ & $64(2.7 \%)$ & $7(1.7 \%)$ & 0.52 \\
\hline M. Musculoskeletal system & $844(15.37 \%)$ & $426(15.59 \%)$ & $369(15.68 \%)$ & $49(12.06 \%)$ & 0.24 \\
\hline N. Nervous system & $945(17.2 \%)$ & $438(16.0 \%)$ & $420(17.9 \%)$ & $87(21.4 \%)$ & 0.05 \\
\hline P. Antiparasitic products & $17(0.3 \%)$ & $12(0.4 \%)$ & $5(0.2 \%)$ & $0(0.0)$ & 0.17 \\
\hline R. Respiratory system & $346(6.3 \%)$ & $150(5.5 \%)$ & $171(7.3 \%)$ & $25(6.2 \%)$ & 0.05 \\
\hline S. Sensory organs & $222(4.0 \%)$ & $104(3.8 \%)$ & $100(4.2 \%)$ & $18(4.4 \%)$ & 0.68 \\
\hline
\end{tabular}

of drug use ( $r=0.89, p=0.007)$ and the mean number of drugs per person $(r=0.88, p=0.009)$ significantly increased with advancing age from 65 to $\geq 95$ years. This increase was mainly due to the significant increase in use of cardiovascular drugs $(p=0.0001)$, low-dose aspirin $(p=$ 0.0001 ), and drugs for the blood and hemopoietic organs $(p<0.0001$; Table 3$)$.

Drug use and GI symptoms

Of the 5,387 subjects who completed the GSRS questionnaire (97.6\% of the total population studied), 1,764 subjects $(32.7 \%)$ reported at least one mild, moderate, and/or severe upper GI symptom. The prevalence of upper GI symptoms was significantly higher in females than in males
(34.2\% vs. $30.9 \%, p=0.011)$. Furthermore, women had a significantly higher prevalence of abdominal pain (17.7 vs. $14.5 \%, p=0.002)$, reflux syndrome $(15.1 \%$ vs. $13.0 \%$, $p=0.027)$, and vomiting ( $3.6 \%$ vs. $1.5 \%, p=0.0001)$ than men, whereas no gender differences were observed regarding the prevalence of indigestion syndrome (males $=23.8 \%$ vs. females $=26.0 \%, p=\mathrm{ns}$ ) and melena and/or hematemesis (males $=0.73 \%$ vs. females $=0.47 \%, p=n s$ ). A significantly higher prevalence of upper GI symptoms was observed in elderly patients who were taking a higher number of drugs (Fig. 1) and who had higher disability as evaluated by the ADL $(p<0.0001)$ and IADL $(p<0.0001)$ scores.

A significantly higher prevalence of upper GI symptoms was identified by univariate analysis in elderly subjects who were taking steroids $(48.8 \%$ vs. $32.4 \%, p=0.0001)$, psycholeptics $(44.6 \%$ vs. $31.5 \%, p=0.0001)$, nonsteroidal anti-
Fig. 1 Prevalence of upper gastrointestinal symptoms in elderly patients, divided according to the number of drugs

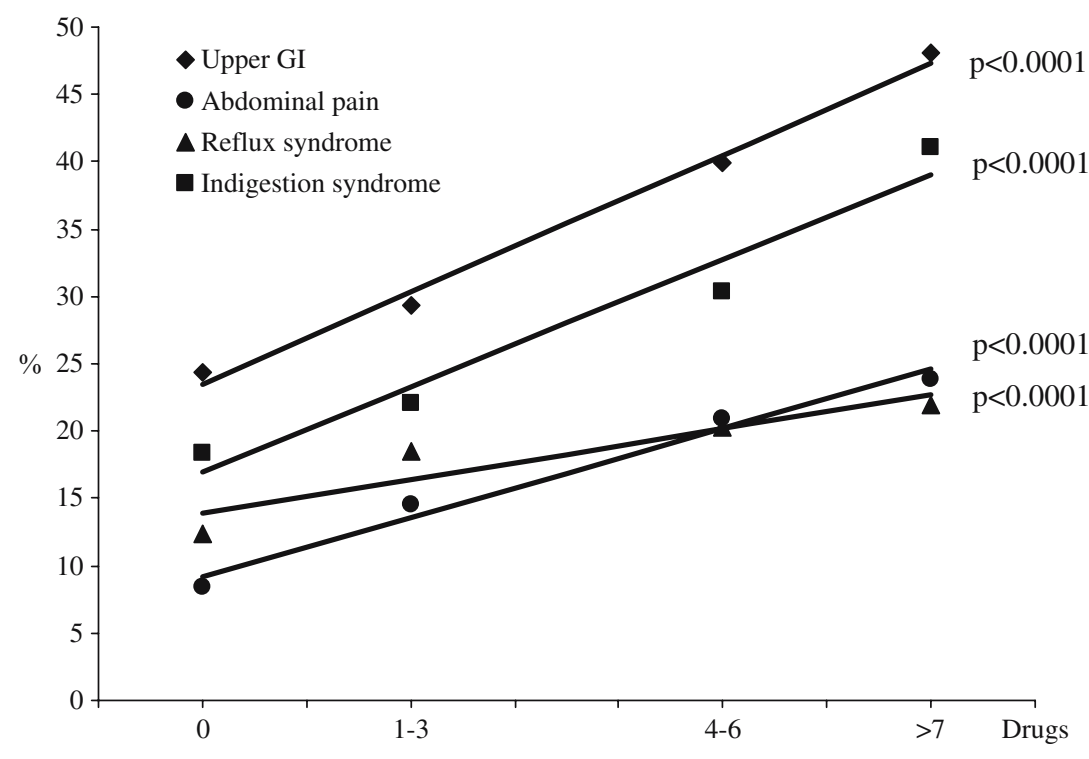


Fig. 2 Prevalence of upper gastrointestinal symptoms in elderly subjects taking specific drugs compared with nonusers

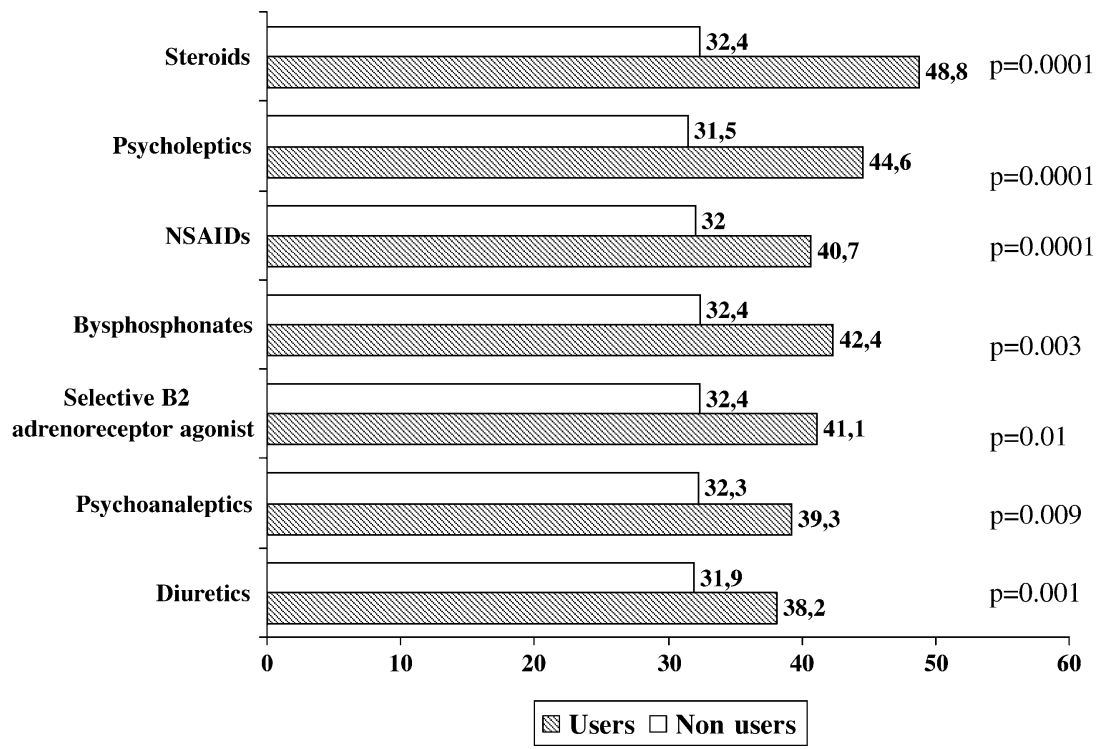

inflammatory drugs (NSAIDs; 40.7 vs. $32 \%, p=0.0001$ ), bisphosphonates ( $42.4 \%$ vs. $32.4 \%, p=0.003)$, selective $\beta_{2}$ adrenoreceptor agonists $(41.1 \%$ vs. $32.4 \%, p=0.01)$, psychoanaleptics $(39.3 \%$ vs. $32.3 \%, p=0.009)$, or diuretics (38.2\% vs. $31.9 \%, p=0.001$ ) compared with nonusers (Fig. 2).

Multivariate regression logistic analysis, adjusted for age, sex, disability (ADL and IADL scores), and individual drug classes that were taken by more than $2 \%$ of patients, demonstrated that steroid, psycholeptic, and NSAID use was significantly associated with abdominal pain syndrome (steroids: $\mathrm{OR}=1.95,95 \% \mathrm{CI}=1.31-2.9, p<0.001$; psycholeptics: $\mathrm{OR}=1.62,95 \% \mathrm{CI}=1.3-2.02, p<0.0001$; NSAIDs: $\mathrm{OR}=1.39,95 \% \mathrm{CI}=1.1-1.75, p<0.005)$, reflux syndrome (steroids: $\mathrm{OR}=1.86,95 \% \mathrm{CI}=1.22-2.83, p<0.004$; psycholeptics: $\mathrm{OR}=1.31,95 \% \mathrm{CI}=1.03-1.68, p<0.025$; NSAIDs: $\mathrm{OR}=1.29,95 \% \mathrm{CI}=1.00-1.66, p<0.05)$, and indigestion syndrome (steroids: $\mathrm{OR}=1.62,95 \% \mathrm{CI}=1.12-2.36, p<0.01$; psycholeptics: $\mathrm{OR}=1.63,95 \% \mathrm{CI}=1.34-1.98, p<0.0001$; NSAIDs: $\mathrm{OR}=1.26,95 \% \mathrm{CI}=1.02-1.56, p<0.03$ ). Moreover, steroid and NSAID use was significantly associated with vomiting $(\mathrm{OR}=2.32,95 \% \mathrm{CI}=1.12-4.77$, and $\mathrm{OR}=2.0$, $95 \% \mathrm{CI}=1.31-3.62$, respectively). Diuretic use was significantly associated with reflux symptoms $(\mathrm{OR}=1.28$, CI $95 \%=1.03-1.58, \quad p=0.022)$ and indigestion syndrome $(\mathrm{OR}=1.32$, CI $95 \%=1.11-1.57, p<0.001)$. Antithrombotic agent use was significantly associated with reflux symptoms $(\mathrm{OR}=1.55$, CI $95 \%=1.13-2.14, p<0.007)$, and selective $\beta_{2}$ adrenoreceptor or other adrenergic agonist use was significantly associated with indigestion syndrome $(\mathrm{OR}=1.45 \mathrm{CI} 95 \%=1.06-2.00, p=0.02)$.

\section{Discussion}

Overall drug use

Results indicate that medication use occurs in $91.6 \%$ of ambulatory subjects over 65 years of age, with a sig- nificantly higher prevalence in women $(92.5 \%)$ than in men $(90.6 \%)$. This high prevalence of drug consumption is very similar to the $91 \%$ and $94 \%$ reported respectively in 594 ambulatory men and women aged over 65 years of age in the United States [1] and to the $82 \%$ and $93 \%$ observed in 1,260 elderly men and women living at home $(1,197$ subjects, $95 \%)$ or in a nursing home $(63$ subjects, $5 \%)$ in Finland [12]. The present study is also in agreement with another Italian study involving data collection from the medical records of GPs for 3,154 elderly: $97 \%$ of women and $96 \%$ of men were taking at least one drug, with a mean of $3.0 \mathrm{drugs} / \mathrm{male}$ and $3.1 \mathrm{drugs} /$ female [13].

In the present study, a mean of 2.8 drugs was observed both in males and females. These data are comparable to results previously reported in elderly outpatients [13-15] but are notably lower than reported for elderly subjects interviewed prior to hospital admission (5.1-6.6 drugs per person) $[16,17]$ or in nursing homes $(7.2-8.1$ drugs per person) [18]. Indeed, in agreement with several studies [1316], a progressive increase in mean medication number was observed with advancing age, from 2.5 in subjects from 65 to 70 years to 3.6 in subjects aged 90 years and over. This cardiovascular agents, low-dose aspirin, and antithrombotic drugs.

Drugs most frequently taken by elderly subjects were cardiovascular (ACE inhibitors $32.4 \%$, calcium antagonists $22.5 \%$ ), low-dose aspirin (20.6\%), GI drugs (19.7\%), nervous system drugs (17.2\%), and musculoskeletal drugs $(15.4 \%)$. All other classes of drugs were prescribed in less than $15 \%$ of subjects. These trends are similar to those reported in other studies [13, 16-18], while differences probably reflect the diversity of study populations, particularly since some studies included subjects with dementia $[19,20]$ or severe disabilities and functional impairments [21]. In the present study, cognitive status was not evaluated. Regarding disability, this study included only elderly subjects who were able to go to the GP's office alone or was mainly due to a significant increase in the use of 
with the help of a family member, thus excluding most patients with severe disabilities or diseases requiring bed rest. Indeed, as expected, according to ADL and IADL scores, respectively, only $4 \%$ and $11.3 \%$ of the elderly patients included in this study presented a moderate and/or severe disability. Looking at the division of patients according to geographical area (northern, central, and southern Italy), patients living in southern or central Italy had a higher prevalence of disability, yet the drug use rate was lower there than in patients living in northern Italy.

The study confirmed that elderly women took significantly more antihypertensives (angiotensin II antagonists), anxiolytics, antidepressants, musculoskeletal drugs, hypolipemics, and vitamins and mineral salts than men. Conversely, men took more cardiac drugs (nitrates and calcium channel blockers), antiplatelet drugs, and antiasthmatic drugs. These findings reflect the gender distribution of diseases in the elderly in Italy [22].

\section{GI symptoms and drug use}

This study demonstrated in a large outpatient population of elderly subjects that over $30 \%$ of patients reported at least one symptom related to the upper GI tract: $25 \%$ of symptoms related to indigestion syndrome, $16 \%$ to abdominal pain, and $14 \%$ to symptoms of reflux disease. These percentages are very similar to the rates reported in previous epidemiological studies in Europe [23-25]. This study, however, reported for the first time in an outpatient general practice population of elderly subjects that the presence of upper GI symptoms was significantly associated with the overall number of drugs as well as with some specific drug classes taken by patients. These findings indirectly support previous studies that demonstrated that GI disorders were the most frequent adverse drug event observed in elderly patients who were admitted to general hospitals in Europe [3] and the United States [4].

In this study, patients were evaluated by means of the GSRS administered to 5,387 patients $(97.6 \%$ of total population) during the interview. No problems were encountered with comprehension or administration of the questionnaire in this population.

This study reported that elderly users of NSAIDs, corticosteroids, and psycholeptics had a significantly higher prevalence of epigastric and/or abdominal pain, reflux symptoms, and indigestion syndrome than nonusers of these classes of drugs. Moreover, NSAID and steroid use was significantly associated with vomiting within the previous week. These findings are in agreement with both epidemiological $[3,5,13,26]$ and clinical studies $[2,4]$ that report in patients aged 65 years and older a significant association between NSAID or steroid use and upper GI symptoms.

The association of upper GI symptoms with psycholeptic use ( $88 \%$ of which was benzodiazepines) might reflect the greater frequency of functional GI disorders, including abdominal pain and/or indigestion syndrome, in subjects with anxiety syndromes and sleep disturbances [27]. The significant association between antithrombotic agents and the presence of reflux symptoms is in agreement with previous clinical studies that indicate adverse upper GI tract effects during chronic treatment with these drugs [2,3]. It is more difficult to explain the significant association between upper GI symptoms and the use of selective $\beta_{2}$ adrenoreceptor/adrenergic agonists or diuretics. Data do exist that suggest a pathophysiological [28] and clinical [29] link between upper GI symptoms and respiratory diseases, especially asthma and chronic obstructive pulmonary disease. Moreover, the renal impairment and electrolyte imbalance that may be related to diuretic use could indirectly influence the presence of GI symptoms, particularly in old age [30]. Nevertheless, no data on the nature of the diseases that affected these patients were available. Moreover, since the study design was cross-sectional, no conclusions about the cause and effect of drug use and the presence of GI symptoms can be made. Other prospective studies will be needed to evaluate the pathophysiological relationships between the use of drugs and the presence of GI symptoms in elderly subjects.

In conclusion, the prevalence of drug use is very high in this elderly outpatient population. The number of drugs and the use of some specific drug classes are significantly associated with the presence of upper GI symptoms. Educational and clinical strategies need to be implemented in order to reduce the GI impact of drug use in elderly people.

Acknowledgment This study was supported by a grant from the FIRI (Fondazione Italiana Ricerca sull'Invecchiamento), Florence, Italy.

\section{The SOFIA Project investigators}

Coordinators/geriatric units

Annoni Giorgio (Monza), Barbagallo Mario (Palermo), Bavazzano Antonio (Prato), Bernabei Roberto (Roma), Biagini Carlo (Pistoia), Cucinotta Domenico (Bologna), Franceschi Marilisa (Vicenza), Guizzardi Giuseppe (Pescara), Granchi Fabrizio (Piacenza), Laguzzi Enzo (Alessandria), Masotti Giulio (Firenze), Maugeri Domenico (Catania), Mazzei Bruno (Cosenza), Nicita Mauro Vittorio (Messina), Nieddu Antonio (Sassari), Noro Gabriele (Trento), Olivari Giuseppe (Venezia), Palummeri Ernesto (Genova), Pilotto Alberto (San Giovanni Rotondo), Policicchio Domenico (Avellino), Postacchini Demetrio (Fermo), Putzu Paolo (Cagliari), Rengo Franco (Napoli), Tardi Salvatore (Matera)

\section{General practitioners}

Abbiati Carla, Alpa Aldo, Antiga Ivo, Antonina Maria Rita, Arnaboldi Leonardo, Ballotti Emanuela, Bargellini Nadia, Barisone Giorgio, Battelli Marco, Beccari Gizela, Bitetti Erasmo, Bologni Anna, Bongera Patrizia, Bortot 
Mario, Bracalenti Luigi, Buonono Giuseppe, Busolo Mirco, Campanini Maria Cristina, Caputo Ludovica, Cartei Alessandro, Cascavilla Paolo, Casciaro Luciano, Casula Eleonora, Cesarone Lucia, Chiesa Damiano, Chiumeo Francesco, Ciciarello Antonio, Cimenti Tullio, Cincotta Gaetano, Corò Gianni, Corona Sergio, Corsini Marco, Cosola Cristoforo, Dainese Antonio, Danza Matteo, De Bastiani Rudy, De Cesare Pasqualina, De Facci Giuseppe, De Lorenzo Roberto, De Vuono Antonio Domenico, Della Piccola Paolo, D'Errico Giovanni, Di Benedetto Giorgio, Dodaro Maurizio, Ercolino Maria, Fatarella Paolo, Fazzari Felice, Fiorese Giampiero, Foco Giuseppe, Formicola Giuseppe, Franchi Fabrizio, Fronges Daniele, Gaetano Maria Assunta, Giordano Gabriella, Guarino Mario, Guasti Daniela, Kuel Albino Mayom, Kusanovic' Marija, Lanzavecchia Daniela, Lofiego Maria Cristina, Lorenzano Elettra, Losi Cristiano, Magrini Fabrizio, Mancini Nicola Maria, Mander Alessandro, Manneschi Mirko, Marchi Riccardo, Maronato Gianni, Marsala Valerio, Mascia Raffaele, Matuonto Vincenzo, Mauceri M. Lucia, Mazzi Pier Alvise, Mezzapica Antonino, Mochi Francesco, Molenda Grazia, Morelli Franco, Morsia Davide, Mosna Maria Clara, Muglia Antonio, Murgia Paolo, Muscetta Maurizio, Muscetta Stelio, Nucci Pietro, Olimpi Giovanni, Orro Walter, Poletto Cristina, Palmieri Isabella Pia, Pastacaldi Guido, Pastori Caterina, Pieresca Gabriele, Pietragalla Mario, Pilo Sebastiano, Poggesi Sonia, Poli Luca, Ricciardi Antonietta, Riggi Vito, Romano Vincenzo, Rossi Tolmino, Saccarello Alberto, Salatino Ada, Salvati Roberto, Sannino Antonio, Santelli Mario, Santucci Adolfo, Saponaro Guido Maria, Schergna Aldo, Schiavone Ciro, Sammarco Renato, Scornavacca Giovanni, Serena Daniela, Silvino Giuseppe, Sistilli Lucia, Soldan Stefano, Soro Aldo, Tatti Romano, Tempestini Laura, Testini Domenico, Tibeloli Carnevali Andrea, Toniolo Barbara, Torselli Roberto, Tremul Luca, Trevisan Francesco, Trifilò Placido, Valente Salvatore, Vannucchi Carlo Enrico, Vencato Paola, Vigotti Glauco, Virdis Gavino, Zaccaro Francesco, Zanzot Stefano, Zingone Filippo Mario Pio, Zirillo Anna Maria.

\section{References}

1. Kaufman DW, Kelly JP, Rosenberg L, Anderson TE, Mitchell AA (2002) Recent patterns of medication use in the ambulatory adult population of the United States. JAMA 287:337-344

2. Pirmohamed M, James S, Meakin S et al. (2004) Adverse drug reactions as cause of admission to hospital: prospective analysis of 18,820 patients. Br Med J 329:15-19

3. Onder G, Pedone C, Landi F, Cesari M, Della Vedova C, Bernabei R et al. (2002) Adverse drug reactions as cause of hospital admissions: results from the Italian Group of Pharmacoepidemiology in the elderly (GIFA). J Am Geriatr Soc 50: 1962-1968

4. Gray SL, Sager M, Lestico MR, Jalaluddin M (1998) Adverse drug events in hospitalized elderly. J Gerontol Med Sci 53A: M59-M63

5. Gurwitz JH, Field TS, Harrold LR et al. (2003) Incidence and preventability of adverse drug events among older persons in the ambulatory setting. JAMA 289:1107-1116
6. Katz S, Downs TD, Cash HR, Grotz RC (1970) Progress in the development of an index of ADL. Gerontologist 10:20-30

7. Lawton MP, Brody EM (1969) Assessment of older people: self-maintaining and instrumental activities of daily living. Gerontologist 9:179-186

8. Svedlund J, Sjodin I, Dotevall G (1988) GSRS-a clinical rating scale for gastrointestinal symptoms in patients with irritable bowel syndrome and peptic ulcer disease. Dig Dis Sci 33:129134

9. L'informatore farmaceutico 2002. OEMF International, Milano 2002. Guidelines for ATC classification. NLN publication no.16. Nordic Council on Medicines, Uppsala

10. Dimenas E, Glise H, Hallerback B et al. (1995) Well-being and gastrointestinal symptoms among patients referred to endoscopy owing to suspected duodenal ulcer. Scand J Gastroenterol 30:1046-1052

11. Dimenas E, Carlsson G, Glise H et al. (1996) Relevance of norm values as part of the documentation of quality of life instruments for use in upper gastrointestinal disease. Scand J Gastroentrol 31(Suppl 221):8-13

12. Linjakumpu T, Hartikainen S, Klaukka T et al. (2002) Use of medications and polypharmacy are increasing among the elderly. J Clin Epidemiol 55:809-817

13. Pilotto A, Franceschi M, Leandro G, Di Mario F on behalf of the Geriatric Gastroenterology Study Group (Società Italiana Gerontologia Geriatria) (2003) NSAID and aspirin use by the elderly in general practice: effect on gastrointestinal symptoms and therapies. Drugs Aging 20:701-710

14. Lernfelt B, Samuelsson O, Skoog I, Landahl S (2003) Changes in drug treatment in the elderly between 1971 and 2000. Eur J Clin Pharmacol 59:637-644

15. Barat I, Andreasen F, Damsgaard EM (2000) The consumption of drugs by 75 -year-old individuals living in their own homes. Eur J Clin Pharmacol 56:501-509

16. Doucet J, Chassagne P, Trivalle C et al. (1996) Drug-drug interactions related to hospital admission in older adults: a prospective study of 1000 patients. J Am Geriatr Soc 44:944 948

17. Flaherty JH, Perry HM 3rd, Lynchard GS, Morley JE (2000) Polypharmacy and hospitalization among older home care patients. J Gerontol A Biol Med Sci 55:M554-M559

18. Beers MH, Ouslander JG, Fingold SF et al. (1992) Inappropriate medication prescribing in skilled-nursing facilities. Ann Intern Med 117:684-689

19. Willis P, Claesson CB, Fratiglioni L et al. (1997) Drug use by demented and non-demented elderly people. Age Ageing 26: 382-391

20. Nygaard HA, Naik M (1999) Drug use in homes for the aged. A comparison between mentally intact and mentally impaired residents. Aging Clin Exp Res 11:186-193

21. Walop W, Amos S, Dalziel W et al. (1999) Prescription and nonprescription drug use among high-risk community-dwelling seniors in Ottawa-Carleton. Can J Clin Pharmacol 6:93100

22. Mannoni A, Briganti MP, Di Bari M et al. (2003) Epidemiological profile of symptomatic osteoarthritis in older adults: a population-based study in Dicomano, Italy. Ann Rheum Dis 62:576-578

23. Jones R, Lydeard S (1989) Prevalence of symptoms of dyspepsia in the community. Br Med J 298:30-32

24. Destro C, Maggi S, Crepaldi G (2003) Epidemiology of gastrointestinal disorders in the elderly. In: Pilotto A, Malfertheiner $\mathrm{P}$, Holt P (eds) Aging and the gastrointestinal tract.Interdisciplinary topics in gerontology, vol 32. Karger Press, Basel, pp $1-11$

25. Diaz-Rubio M, Moreno-Elola-Olaso C, Rey E et al. (2004) Symptoms of gastro-oesophageal reflux: prevalence, severity, duration and associated factors in a Spanish population. Aliment Pharmacol Ther 19:95-105

26. Talley NJ, Evans JM, Fleming KC et al. (1995) Nonsteroidal anti-inflammatory drugs and dyspepsia in the elderly. Dig Dis Sci 40:1345-1350 
27. Vege SS, Lcke GR, Weaver AL et al. (2004) Funtional gastrointestinal disorders among people with sleep disturbances: a population-based study. Mayo Clin Proc 79:1501-1506

28. Stein MR (2003) Possible mechanisms of influence of esophageal acid on airway hyperresponsiveness. Am J Med 115 (Suppl 3A):S55-S59
29. Raiha IJ, Ivaska K, Sourander LB (1992) Pulmonary function in gastro-oesophagal reflux disease of elderly people. Age Ageing 21:368-373

30. Zuccalà G, Pedone C, Cocchi A et al. (2000) Older age and inhospital development of hypokalemia from loop diuretics: results from a multicenter survey. GIFA Investigators (Multicenter Italian Pharmacoepidemiologic Study Group). J Gerontol A Biol Med Sci 55:M232-M238 